\title{
PlayPhysics: Emotional Games Learning Environment for Teaching Physics
}

\author{
K.C. Muñoz Esquivel, M.Sc. \\ Intelligent Systems Research Centre \\ School of Computing and Intelligent Systems \\ Faculty of Computing and Engineering, University of Ulster, Magee, \\ BT48 7JL, Derry/Londonderry, Northern Ireland \\ E-mail: munoz_esquivel-k@email.ulster.ac.uk \\ 100 Day Review Report \\ December, 2008
}

Supervisors: Prof. Paul Mc Kevitt \& Dr. Tom Lunney

\begin{abstract}
Research in the field of learning technologies is focused on finding the most effective way in which virtual learning environments (VLEs) and educational games comprehend and respond to students. Computer based tutoring is attempting to be comparable to one-to-one human tutoring. To address the stated problems, this research proposal investigates a new generation of adaptable affective intelligent tutoring systems (ITSs), with enhanced student and adaptable tutor models for flexible learning. This proposal focuses on improving the student model to represent aspects of the student's personality and emotion. As a primary research target, the adaptable tutor model will convey cognitive feedback and reflect some aspects of the student's personality and emotion. The implementation of the described student and tutor models will involve the evaluation of AI techniques such as Hidden Markov Models (HMMs), Bayesian networks and influence diagrams. This research will implement the virtual learning environment, PlayPhysics, which will include educational games to teach Physics to engineering students. PlayPhysics will be implemented using the Olympia architecture. An educational game (control group) and an adaptable educational game (experimental group) will be used for evaluation. Experimental results will determine the enhanced comprehension of the student. Reflection will be offered as an affinity seeking strategy throughout the student's learning. Potential AI software tools, e.g. Elvira and JAHMM, are being evaluated to model the enhanced student representation and the adaptable tutor models. The development of either of these two models has a potential research contribution. Finally, comparing PlayPhysics to other work, it is evident that innovating aspects are detecting the student's personality changes while interacting with PlayPhysics and modulating the educational game to reflect the emotional and personal attributes of the learner.
\end{abstract}

Keywords: Affective computing, serious games, intelligent tutoring system, PlayPhysics, virtual learning environments.

\section{Introduction}

Virtual learning environments (VLEs) and educational games have proven their effectiveness (Cheng et al., 2007; Sucar \& Noguez, 2008). Their ultimate goals are attaining a successful feedback response and demonstrating an accurate student understanding comparable with human tutoring (Sarrafzadeh et al., 2008). Several complex challenges are involved in the stated problems and to overcome them, artificial intelligence (AI) techniques can be used. The aim of this research is to investigate the implementation of a new generation of adaptable affective intelligent tutoring systems (ITSs) that relies on an enhanced student and adaptable tutor models to achieve more flexible learning. AI techniques, such as Hidden Markov Models (HMMs), influence diagrams and Bayesian networks, will be evaluated for the implementation of the enhanced student model and adaptable tutor model. This research will focus on developing an adaptable model to represent the student's personality and emotional state during the learning process. This will involve investigating affinity seeking strategies to be incorporated into the feedback so as to optimise the student experience. To validate the approach, PlayPhysics, a virtual learning environment using the Olympia architecture (Muñoz, 2008) will be developed. PlayPhysics will include educational games for teaching Physics at undergraduate level. This proposal comprises the innovative aspects of detecting the 
student's personality changes while interacting with PlayPhysics and modulating the educational game to reflect the emotional and personal attributes of the learner. Section 2 covers the literature review of this proposal. In section 3 the aims and objectives, research methodology, software analysis, design and development plan of PlayPhysics are discussed. In section 4, PlayPhysics is compared to related work. In section 5 this proposal concludes by outlining its benefits.

\section{Literature review}

This section covers key areas in the field of educational technologies, research methodologies and the stated problems that relate to this research proposal.

\subsection{VLEs}

VLEs have shown advantages when compared with traditional education, such as personalised attention and reduced teaching cost per student in space, time and money (Sorensen \& Ó Murchú, 2006). The VLEs' existing challenges are the representation of the knowledge domain, the conceptualisation of student's knowledge, emotion and personal disposition and the attainment of an adaptable learning progression (Du Boulay \& Luckin, 2001). Existing enquiries are how to offer tutoring comparable to one-to-one human tutoring (Sarrafzadeh et al., 2008) and how to retain the student's motivation (D'Mello et al., 2008). Whether educational games are more effective than VLEs is an open investigation, although it been shown that students learn in a similar way, they experience more motivation with educational games (Kuo, 2007).

\subsection{Educational games}

Educational games are intelligent and interactive learning environments where students learn through experiencing the immediate consequences of their actions and emotional involvement. Learning and entertaining goals are central to their design (Sykes, 2006). Therefore, educational games are highly appealing from the student's perspective. However, open enquiries are how to ensure that the student thinks on the domain knowledge whilst learning to play a game effectively (Conati, 2002), how to accomplish equilibrium between content and engagement and how to offer successful pedagogical instruction. Research is attempting to augment the efficacy of educational games by detecting and responding to emotion during play (Sykes, 2006).

\subsection{Affective computing}

Affective computing, a research area originated by Rosalind Picard, is focused on enabling computers to express and recognise affect (Picard, 1995). Therefore, existing challenges are distinguishing accurately an emotional state under real constraints and expressing believable emotion. The development of cognition without emotion is considered unattainable (Barsalou et al., 2007). Teaching is a dialogue that is inherently social (D'Mello et al., 2008), where cognitive and emotional messages between teacher and student influence the course of interaction and its result. Therefore, affective computing offers the possibility of making VLEs and educational games as effective as human tutoring. Sykes (2006) introduces affective gaming that is the application of affective computing technologies to the domain of digital games.

\subsubsection{Recognition of emotion and personality in AI}

Recognising emotion under real constraints is a discussion that has involved using cameras or sensors for detecting the emotion and processing algorithms for determining the emotion (D'Mello et al., 2008). Investigation has focused on detecting the basic emotions outlined by Ekman \& Friesen (1978). Conati (2002) has recognised emotions using the Ortony, Clore and Collins (OCC) model (Ortony et al., 1990) that is based on the desirability of personal goals and personal differences. Alternatively, Razek et al. (2006) have explored the user's selection of a colour sequence. Hardware devices have been developed to sense emotions (Sykes, 2006), but they are not useful in online learning. Different sources such as natural language (Wang \& Guan, 2008) and body language (D'Mello et al., 2008) have been utilised to detect affect. Some artificial intelligence (AI) techniques that have been used to identify emotion are HMMs, Bayesian networks and influence diagrams (Wang \& Guan, 2008; Conati, 2002).

The learning experience must be personalised and amiable (Li et al., 2007) and how to attain both qualities is a topic of open investigation in the field of computational technologies. There is not a universal psychological theory to identify personality. Some of the most commonly used models in computing are 
Myers-Briggs and Big Five (Conati, 2002; Abrahamian et al., 2004). Research suggests that a person perceives functional and aesthetic qualities in an interactive object. The latter comprises motivational and identity features (Burmester \&. Dufner, 2006). Selecting the game's audience and its gameplay correctly is critical to the reception of the game. The Demographic Game Design model (DGD1), based on MyersBriggs, enhances the design perspective to address the players' needs (Bateman \& Boon, 2006).

\subsubsection{Affective intelligent tutoring systems}

ITSs have offered an incomplete representation of the student and limited scope and adaptability in their teaching strategies when compared with those provided by a human (Sarrafzadeh et al., 2008; Du Boulay \& Luckin, 2001). Researchers are attempting to add capabilities to recognise and express affect (Burleson \& Picard, 2007). They seek to accomplish a reliable representation of the student's emotional state and hence provide effective cognitive feedback and believable emotional interaction (Sarrafzadeh et al., 2008). An ITS usually comprises a domain knowledge, communication and pedagogical modules and a student model. Adaptability is usually addressed within the student model. Investigation with students and human tutors has shown that the teaching and learning process involves affinity seeking strategies and the tutor's response is influenced by the history of interaction with the student (Alexander et al., 2008).

\subsubsection{Empathic feedback and pedagogical agents}

In an empathic process an observer experiences the emotion or intention of the observed thereby understanding it (Bischof-Köhler, 2004). Mimicking empathy is one of the levels of abstraction required to attain a computational teaching-learning experience comparable to one involving only humans. The quest on is how much detail the computing tutors need to have to imitate humans (Du Boulay \& Luckin, 2001). Adapting the tutoring response involves selecting pedagogical actions and motivational strategies and handling appropriate resources to address the student's negative emotions (D'Mello et al., 2008). Researchers have used narrative for teaching social education in VLEs. They evoke the student's empathy to encourage understanding (Dias et al., 2006). Pedagogical agents are often used to provide believable emotional interaction, since their presence results in positive effects on the student's perception (Conati, 2002). But the advantage of using pedagogical agents cannot be generalised, since not all the students have the same perspective.

To summarise, attaining an accurate representation of the student and adapting the pedagogical feedback to offer affinity seeking strategies, are goals that involve several complex challenges, which can been addressed only by using AI techniques. Accordingly, it is essential that ITSs evolve to a level that enables them to communicate with the student in a way that takes into account the students' changing intellectual and emotional state.

\section{Research project proposal}

Since the development of human cognition without emotion is unattainable, it is essential that intelligent tutoring systems include affective features in their student representation and feedback. As a result, Affective computing has the potential of advancing Computer based tutoring. Therefore this proposal is focused on implementing PlayPhysics, an online learning environment embodying a new generation of adaptable affective ITSs. This section discusses how this new generation of ITSs attains its features and the design of PlayPhysics.

\subsection{Hypothesis and statement of the aims and objectives}

This research proposal is focused on addressing mainly a more accurate student representation and providing a preliminary approach to adapt pedagogical feedback to attain affinity seeking strategies. The aim is to investigate the implementation of an adaptable affective ITS, which consists of an enhanced student representation and adaptable tutor models for flexible learning. The adaptable affective ITS will be used to develop educational technologies that have a more accurate perception of the student, recognising aspects of the student's emotion and personality. The student feedback will be modulated, offering cognitive instruction and reflecting the student's personal and emotional disposition. The student's reflection will be used as an initial approach to attain affinity seeking strategies. The hypothesis is to analyse whether a more precise comprehension of the student and the reflection of such comprehension combined with cognitive feedback, have a significant effect on the student's learning. To validate the approach, PlayPhysics, a virtual learning environment will include educational games for teaching Physics 
to engineering students, will be implemented. PlayPhysics will be developed using Olympia architecture. Olympia (Muñoz, 2008) will be enhanced through the implementation of an adaptable affective ITS. To recognise aspects of the student's personality and emotion, the challenge of selecting the most suitable AI techniques must be addressed. Potential AI techniques are HMMs, Bayesian networks and influence diagrams, which represent uncertainly. If positive results are attained from this research, a hope is to modify the adaptable tutor model to implement more complex affinity seeking strategies and embody an ideal teacher.

\subsection{Rationale and research methodology}

An educational game can be modulated to reflect affinity. A human tutor adapts his or her behaviour according to the student's responses. The student's emotions are expressions of motivation, but the students' individual differences do not allow their general interpretation. Personality can be conceptualised as the context where emotion and cognition can be more accurately comprehended. Accordingly, the chosen methodology involves implementing PlayPhysics, which will include educational and adaptable educational games for teaching Physics to engineering students. The undergraduate students are between 18 and 24 years old and will be divided equally into control (educational game) and experimental groups (adaptable educational game). The main difference between the educational and the adaptable educational games will be that the latter will be enabled to recognise and reflect aspects of the student's emotion and personality. Qualitative and quantitative questionnaires will be applied before and after the students' interaction with the corresponding educational game. Experimental results will be analysed by statistical methods.

\subsection{Requirements and potential software analysis}

In 2007 the Head of Department of Basic Sciences at Tecnológico de Monterrey University in Mexico City expressed a need for finding new ways of engaging and challenging students whilst teaching Physics. The on-line application, PlayPhysics, and educational games were suggested. PlayPhysics will be implemented following a web-based learner-centred paradigm (Du Boulay \& Luckin, 2001) to address learner's needs and to enable the student centred learning. The Constructionist Design Methodology (Thórrison et al., 2004) will be used to integrate and coordinate the several functionalities of PlayPhysics and communicate a consistent behaviour. In addition, the First Principles method, which comprises a long view of the game design process, will be applied (Bateman \& Boon, 2006). Pedagogical strategies and student and adaptable tutor models will be structured according to the methodologies and theories derived from expert human teachers and psychologists (Du Boulay \& Luckin, 2001). Unified modelling language (UML) will be used to specify the abstract model of PlayPhysics (IBM, 2003). JAVA (Sun Microsystems, 2008a) in combination with MySQL (Sun Microsystems, 2008b) will be explored as options to attain a secure on-line environment. 3D Studio Max (Autodesk, Inc., 2008) and Blender (Blender.org, 2008) are potential tools to attain high quality 3D modelling. Elvira (Díez, 2005), Hugin Lite (Hugin Expert A/S, 2004) and JAHMM (François, 2006) are alternatives to model probabilistic models. To address the student's emotion, the OCC model in combination with different modalities, will be investigated. To classify aspects of the student's personality and modulate the educational game's feedback, Myers-Briggs theory and DGD1 will be examined.

\subsection{PlayPhysics design}

PlayPhysics will be implemented using the Olympia architecture. The PlayPhysics architecture shown in Figure A.3, Appendix A, comprises static and dynamic interaction modules. A static module does not change in real-time according to the pedagogical actions or student's behaviour, whilst a dynamic module adapts. The game mechanics module, which manages the challenges-actions relation, will be modulated to reflect identity expressions. The expressions combined with cognitive feedback will show comprehension of the student's actions and necessities. The modulation of the game mechanics module describes a potential innovating aspect, since it enables the educational game to attain flexibility for embodying the student's personal and emotional attributes. Reflection will offer an initial approach to attain affinity seeking strategies. The teaching and learning AI module is an adaptable affective ITS, which comprises enhanced student and adaptable tutor models, shown in Appendix A, Figures A.1 and A.2 respectively. The development of any of these two modules has a potential contribution. The student cognitive model is a Bayesian network, which infers the student's knowledge from his interaction whilst attempting to attain specific learning goals. The adaptable tutor model is another innovating aspect, since it assists the student 
model to attain learning flexibility. Probabilistic models are being evaluated to determine their viability to model the student's affective and adaptable tutor models.

\subsection{Project development}

The project plan addressing the execution of this research is shown in Table C.1, Appendix C. The research plan was divided into activities, which have been classified as Milestones, Designing, testing and deploying phases, Data Collection, Experimentation, Background and focal theory, writing up thesis, Publications and Research training program. The category Milestones involves due dates and crucial events in the lifetime of the research project, such as the $1^{\text {st }}$ year confirmation report, the $2^{\text {nd }}$ year poster presentation and $3^{\text {rd }}$ year student conference presentation. Designing, testing and deploying phases are decisive activities to ensure the quality of the research project prototype. Data Collection includes the design and application of questionnaires to gather requirements and experimentation results. Experimentation comprises the students' interaction with the corresponding educational game to test the project's hypothesis. Background and focal theory covers the investigation performed to review the state of the art, the potential methodologies and software tools. Writing up thesis addresses the period of time to write the doctoral thesis. The category Publications describes the potential targets to publish articles related to the first year of the research, such as the International Symposium of Electronic Arts (ISEA 09) and the Irish Conference on Artificial Intelligence and Cognitive Science (AICS 09). The objective of publishing is acquiring experience and research skills. The publications to be accomplished in the second and the third years will be planned at the end of the first and second years respectively. Finally, the category Research training program depicts the period in which abilities, related to the successful completion of the research project, will be attained.

\section{Relation to previous work}

A comparison of PlayPhysics with other affective intelligent tutoring applications is shown in Table B.1, Appendix B. PlayPhysics is the only application that offers game modulation which takes into account the student's understanding, emotion and personality. It is noticeable from the comparison of PlayPhysics with AutoTutor and Prime Climb, that research has not explored completely the adaptation of an ITS's pedagogical output using advanced AI technologies. Investigation, such as the one depicted by the application Easy with Eve and EMASPEL, is just beginning to focus on enhancing the pedagogical response using superior AI techniques such as case-based reasoning and agents to accomplish that objective. EMASPEL and Fear Not! use an intelligent agent (IA) for implementing their teaching strategies. PlayPhysics uses an ITS because, as perceived from the EMASPEL research, various IAs are required to perform the functions of an ITS. Finally, this research proposal will examine the use of potential source modalities, such as natural language or colour selection, to attune to the student's emotional state. In addition, this proposal also intends to enhance the student model through identifying aspects of the student's personality. Another objective is to adapt the pedagogical response to reflect the student's personal and emotional disposition as a first approach to offering affinity seeking strategies.

\section{Conclusion}

Computer based tutoring is attempting to be comparable to one-to-one human tutoring. To achieve this goal, the challenges of attaining an accurate representation of the student and offering successful and believable feedback must be attained. Until now, the detail in which intelligent tutoring systems must mimic experienced human tutors is not clearly defined. This research endeavours to implement PlayPhysics, an online learning environment for teaching Physics at undergraduate level. This proposal describes the aims and objectives, rationale, research methodology, potential software analysis, design and development plan of PlayPhysics. From the comparison of PlayPhysics with other affective intelligent learning environments, innovative aspects can be enumerated, such as a new generation of affective adaptable ITSs that attain learning flexibility through an enhanced student representation and adaptable tutor models, the improvement of the student representation by recognising aspects of the student's personality and the modulation of an educational game to reflect cognitive, emotional and personal aspects of the learner. The pedagogical response will be perceptible through the graphical look \& feel interface. Reflection will be used as a first research approach to attain affinity seeking strategies. Finally, because of its stated benefits, PlayPhysics aims to have a positive influence over the student's learning. 


\section{References}

Abrahamian, E., Weinberg, J., Grady, M. \& Stanton, M.C. (2004) The effect of personality-aware Computer-Human Interfaces on Learning, Journal of Universal Computer Science, 4(1), 27-37.

Alexander, S., Sarrafzadeh, A. \& Hill, S. (2008) Foundation of an affective tutoring system: learning how human tutors adapt to student emotion, International Journal of Intelligent Systems Technologies and Applications , 4(3/4), 355-367.

Autodesk, Inc. (2008) Autodesk - Autodesk 3ds Max [online]. Available from: http://usa.autodesk.com/adsk/servlet/index?siteID=123112\&id=5659302 [Accessed $25^{\text {th }}$ November 2008].

Barsalou, L., Breazeal, C. \& Smith, L. (2007) Cognition as Coordinated non-cognition. Cognitive Processing, 8(2), 79-91.

Bateman, C. \& Boon, R. (2006) $21^{\text {st }}$ Century game design, 3-102, Hingham, Massachusetts: Charles River Media, Inc.

Bischof-Köhler, D. (2004) Empathy, Compassion and Cruelty, and How They Connect. Presentation at Einstein Forum Potsdam: Zivilisationsbruch mit Zuschauer. Gestalten des Mitgefühls $9^{\text {th }}-11^{\text {th }}$ December Kaarst, Germany [online]. Available from: http://www.bischof.com/mat/bischof-koehler_empathy.pdf [Accessed $21^{\text {st }}$ November 2008].

Blender.org (2008) blender.org - Home [online]. Available from: http://www.blender.org/ [Accessed 25 ${ }^{\text {th }}$ November 2008]

Burleson, W. \& Picard, R.W (2007) Evidence for Gender Specific Approaches to the Development of Emotionally Intelligent Learning Companions, IEEE Intelligent Systems, Special issue on Intelligent Educational Systems, 22(4), 62-69.

Burmester, M. \&. Dufner, A. (2006) Designing the simulation aspect of hedonic quality - an exploratory study. In: Pivec, M. ed. Affective and emotional aspects of human-computer interaction, 2006, 3-7, Netherlands, Amsterdam: IOS Press.

Cheng, H.N.H., Deng, Y.H., Chang, S.B. \& Chan, T.W. (2007) EduBingo: Design of multi-level challenges of a digital classroom game, In: Digital Game and Intelligent Toy Enhanced Learning, The $1^{\text {st }}$ IEEE International Workshop on digital game and intelligent toy enhanced learning, 26-28 March , Jhongli City, $11-18$.

Conati, C. (2002) Probabilistic assessment of user's emotions in educational games. Journal of Applied Artificial Intelligence, special issue on Merging cognition and affect in HCI, 16(7-8), 555-575.

D'Mello, S., Jackson, T., Craig, S., Morgan, B., Chipman, P., White,H., Person, N., Kort, B., el Kaliouby, R., Picard., R.W. \& Graesser, A. (2008) AutoTutor Detects and Responds to Learners Affective and Cognitive States In: Workshop on Emotional and Cognitive Issues at the International Conference of Intelligent Tutoring Systems, 23-27 June, Montreal, Canada.

Dias, J., Paiva, A., Vala, M., Aylett, R., Woods, S., Zoll, C. \& Hall, L. (2006) Empathic characters in computer-based personal and social education, In: Pivec, M. ed. Affective and emotional aspects of humancomputer interaction, 2006, 246-254, Netherlands, Amsterdam: IOS Press.

Díez, J. (2005) Elvira [online]. Available from: http://www.ia.uned.es/ elvira/index-en.html [Accessed 25th November 2008]. 
Du Boulay, B. \& Luckin, R. (2001) Modelling human teaching tactics and strategies for tutoring systems, International Journal of Artificial Intelligence in Education, 12, 235-256.

Ekman, P. \& Friesen, W. V. (1978) Facial Action Coding System: A Technique for the Measurement of Facial Movement, Palo Alto, CA: Consulting Psychologists Press.

François, J. (2006) JAHMM - An implementation of HMM in Java [online]. Available from: [Accessed 25th November 2008].

Hugin Expert A/S (2004) HUGIN EXPERT- Hugin Lite [online]. Available from:

http://www.hugin.com/Products_Services/Products/Demo/Lite/ [Accessed $25^{\text {th }}$ November 2008]

IBM (2003) UML basics: An introduction to the Unified Modeling Language [online]. Available from: http://www.ibm.com/developerworks/rational/library/769.html [Accessed 25th November 2008].

Kuo, M. J. (2007) How does an online game based learning environment promotes student's intrinsic motivation for learning natural science and how does it affect their learning outcomes?, In: Digital Game and Intelligent Toy Enhanced Learning, The $1^{\text {st }}$ IEEE International Workshop on digital game and intelligent toy enhanced learning, Jhongli City, March 26-28, 135-142.

Li, T., Qju, Y., Yue, P. \& Zhongh, G. (2007) Exploiting model of personality and emotion of learning companion agent, In: International conference on Computer Systems and applications AICCSA '07 IEEE/ACS, Amman, May 13-16, 860-865.

Muñoz, K. (2008) Investigation of a hybrid learning environment for teaching Physics using the Olympia architecture, M.Sc. dissertation, University of Ulster, Magee.

Neji, M. \& Ben Ammar, M. (2007) Agent-based Collaborative Affective e-learning framework, The Electronic Journal of e-Learning, 5(2), 123-134.

Ortony, A., Clore, G.L. \& Collins, A. (1990) The cognitive structure of emotions, Cambridge, NY:

Cambridge University Press.

Picard R.W. (1995) Affective Computing, 1-26, Mass, Cambridge: Perceptual Computing Section, Media Laboratory, Massachusetts Institute of Technology.

Razek, M.A., Chaffar, S, Frasson, C. \& Ochs, M. (2006) Using machine-learning techniques to recognize emotions for on-line learning systems, In: Pivec, M. ed. Affective and emotional aspects of humancomputer interaction, 2006, 255-265, Netherlands, Amsterdam: IOS Press.

Sarrafzadeh, A., Alexander, S. Dadgostar, F. Fan ,C. \& Bigdeli ,A. (2008) How do you know that I don't understand? A look at the future of intelligent tutoring systems, Computers in Human Behavior, 24(4), 3421363.

Sorensen, K.E. \& Ó Murchú, D. (2008) Enhancing learning through technology, British Journal of Educational Technology, 39(4), 749-769.

Sucar, L.E. \& Noguez, J. (2008) Chapter 10: Student Modeling, 173-185. In Pourret, O., Naim, P., Marcot, B. Bayesian Networks: A Practical Guide to Applications, United Kingdom: J. Wiley \& Sons.

Sun Microsystems (2008a) Developer resources for Java technology [online]. Available from: http://java.sun.com/. [Accessed $25^{\text {th }}$ November, 2008].

Sun Microsystems (2008b) MySQL: The world's most popular open source database [online]. Available from:http://www.mysql.com/ [Accessed $25^{\text {th }}$ November, 2008]. 
Sykes J. (2006) Affective gaming: Advancing the argument for game-based learning. In: Pivec, M. ed. Affective and emotional aspects of human-computer interaction, 2006, 3-7, Netherlands, Amsterdam: IOS Press.

Thórrison, K. R., Benko, H., Abramov, D., Andrew, A., Maskey, S. \& Vaseekaran, A. (2004) Constructionist design methodology for interactive intelligences, A.I. Magazine [online], Winter, 25(4). Available from: http://www.aaai.org/ojs/index.php/aimagazine/article/viewArticle/1786 [Accessed $11^{\text {th }}$ December 2008]

Wang, Y. \& Guan, L. (2008) Recognizing human emotional state from audiovisual signals, IEEE Transactions in Multimedia, 10(5), 936-946. 


\section{Appendices}

\section{Appendix A. PlayPhysics design}

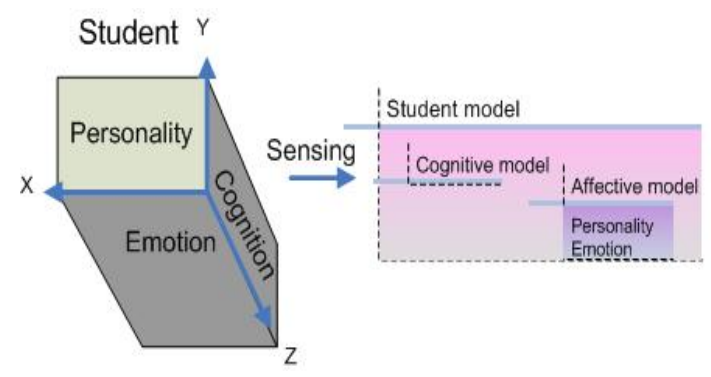

Figure A.1. Enhanced student model

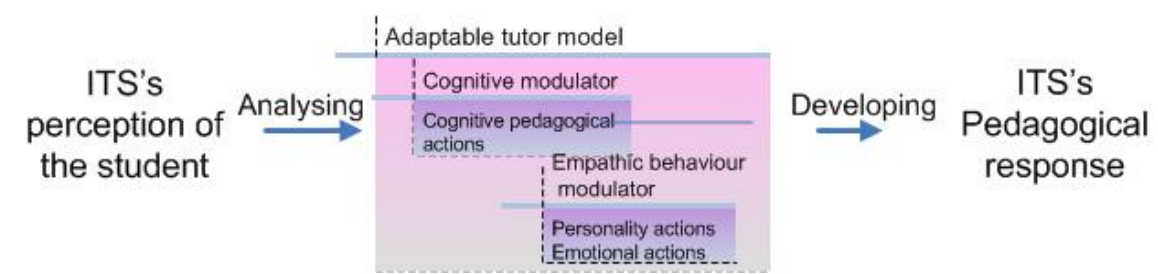

Figure A.2. Adaptable tutor model
ITS's

Classifying perception of the student

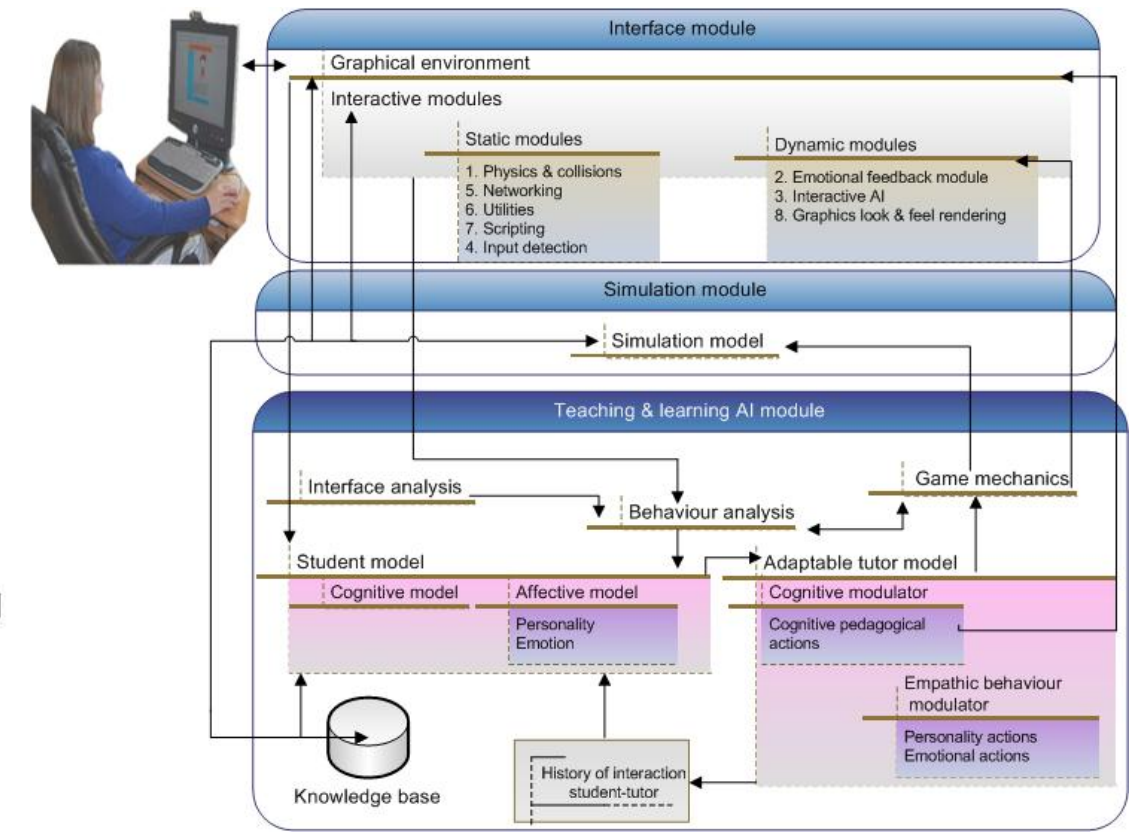

Figure A.3. Architecture of PlayPhysics

\section{Brief description of the static interaction modules}

1. Physics and collisions module contains all the physics-and-maths driven objects used to increase the level of realism during simulation.

4. Input detection module senses and handles the input

5. Networking module transmits data across the network

6. Utilities module contains other tools such as timers and resource managers.

7. Scripting module allows external control of the application.

\section{Brief description of the dynamic interaction modules}

2. Emotional feedback module uses sound and colours to set the student's mood.

3. Interactive AI module is used to make a learning environment believable.

8. Graphics Look \& Feel Rendering module contains all the graphic resources and manages them and the scenes in real-time. 
Appendix B. Comparison to other work

\begin{tabular}{|c|c|c|c|c|c|c|c|c|c|c|c|c|c|c|c|}
\hline \multirow[t]{2}{*}{ Application } & \multirow[t]{2}{*}{$\begin{array}{l}\text { Research } \\
\text { Reference }\end{array}$} & \multicolumn{2}{|c|}{$\begin{array}{l}\text { Tutoring } \\
\text { modeling }\end{array}$} & \multicolumn{2}{|c|}{$\begin{array}{c}\text { Education } \\
\text { technologies }\end{array}$} & \multirow[t]{2}{*}{$\begin{array}{l}\text { Teaching } \\
\text { subject }\end{array}$} & \multirow[t]{2}{*}{ Teaching strategy } & \multirow[t]{2}{*}{$\begin{array}{l}\text { Emotion detection } \\
\text { modalities }\end{array}$} & \multirow{2}{*}{$\begin{array}{c}\text { Detection of } \\
\text { personality } \\
\text { aspects }\end{array}$} & \multirow[t]{2}{*}{ Online } & \multicolumn{3}{|c|}{ Feedback resource } & \multirow{2}{*}{\begin{tabular}{|c|} 
Al technique to \\
recognise \\
emotions
\end{tabular}} & \multirow[t]{2}{*}{$\begin{array}{l}\text { Al technique to } \\
\text { adapt feedback }\end{array}$} \\
\hline & & $\mathrm{ITS}^{6}$ & $1 A^{5}$ & $\begin{array}{c}\text { Educational } \\
\text { game }\end{array}$ & $\mathrm{VLE}^{7}$ & & & & & & \begin{tabular}{|c|} 
Game \\
modulation
\end{tabular} & $\begin{array}{c}\text { Pedagogical } \\
\text { agent }\end{array}$ & \begin{tabular}{|c|}
$\begin{array}{c}\text { Synthetic } \\
\text { characters }\end{array}$ \\
\end{tabular} & & \\
\hline Prime Climb & $\begin{array}{l}\text { Conati } \\
(2002)\end{array}$ & $\checkmark$ & $x$ & $\checkmark$ & $x$ & Maths & $\begin{array}{c}\mathrm{GBL}^{2} \text {, Learning by } \\
\text { doing, collaborative } \\
\text { learning, learning by } \\
\text { teaching }\end{array}$ & Biometrics & $x$ & $x$ & $x$ & $\checkmark$ & $x$ & Influence diagram & Production rules \\
\hline Fear Not! & $\begin{array}{c}\text { Dias et. al } \\
\text { (2006) }\end{array}$ & $x$ & $\checkmark$ & $x$ & $\checkmark$ & \begin{tabular}{|c|} 
Personal, social \\
\& health \\
education
\end{tabular} & $\begin{array}{l}\text { Collaborative learning } \\
\text { \& dynamic narrative }\end{array}$ & $x$ & $x$ & $\checkmark$ & $x$ & $x$ & $\checkmark$ & $x$ & $\begin{array}{c}\text { Agents } \\
\text { architecture }\end{array}$ \\
\hline EMASPEL & $\begin{array}{l}\text { Neji \& Ben } \\
\text { Ammar } \\
\text { (2007) }\end{array}$ & $x$ & $\checkmark$ & $x$ & $\checkmark$ & \begin{tabular}{|c|}
$\begin{array}{c}\text { Communications } \\
\text { technology }\end{array}$ \\
\end{tabular} & $\begin{array}{c}\text { Learning by teaching, } \\
\text { learning by } \\
\text { observation \& } \\
\text { collaborative learning }\end{array}$ & facial gestures & $x$ & $\checkmark$ & $x$ & $\checkmark$ & $x$ & $\begin{array}{l}\text { Multi agent } \\
\text { system }\end{array}$ & Tutoring agent \\
\hline $\begin{array}{l}\text { Easy with } \\
\text { Eve }\end{array}$ & $\begin{array}{c}\text { Sarrafzadeh } \\
\text { et. al } \\
\text { (2008) } \\
\end{array}$ & $\checkmark$ & $x$ & $x$ & $\checkmark$ & Maths & \begin{tabular}{|c|} 
PBL $^{1}$, enquiry, \\
collaborative learning, \\
learning by teaching, \\
\end{tabular} & $\begin{array}{c}\text { facial gestures \& body } \\
\text { language }\end{array}$ & $x$ & $\checkmark$ & $x$ & $\checkmark$ & $x$ & $A N N^{3}$ & $\begin{array}{l}\text { Case-based } \\
\text { reasoning }\end{array}$ \\
\hline AutoTutor & \begin{tabular}{|c|} 
D'Mello et. al \\
(2008)
\end{tabular} & $\checkmark$ & $x$ & $x$ & $\checkmark$ & $\begin{array}{l}\text { Newtonian } \\
\text { Physics }\end{array}$ & $\begin{array}{c}\mathrm{PBL}^{1} \text {, learning by } \\
\text { teaching, enquiry, } \\
\text { learning by } \\
\text { observation } \\
\end{array}$ & $\begin{array}{c}\text { natural language, facial } \\
\text { gestures \& body } \\
\text { language }\end{array}$ & $x$ & $x$ & $x$ & $\checkmark$ & $x$ & \begin{tabular}{|c|} 
Supervised \\
learning methods
\end{tabular} & Production rules \\
\hline PlayPhysics & \begin{tabular}{|l} 
Muñoz et. al \\
(2008- 2011)
\end{tabular} & $\checkmark$ & $x$ & $\checkmark$ & $\checkmark$ & Physics & $\begin{array}{c}\mathrm{PBL}^{1}, \mathrm{GBL}^{2} \text { \& learning } \\
\text { by observation }\end{array}$ & $\begin{array}{c}\text { natural language, facial } \\
\text { gestures, narrative } \\
\text { progression, goals } \\
\text { definition or selection of } \\
\text { colours }\end{array}$ & $\checkmark$ & $\checkmark$ & $\checkmark$ & $\checkmark$ & $x$ & \begin{tabular}{|c|}
$H M M^{4}$ or \\
Bayesian network \\
or influence \\
diagram \\
\end{tabular} & \begin{tabular}{|l}
$\mathrm{HMM}^{4}$ or \\
Bayesian network \\
or influence \\
diagram
\end{tabular} \\
\hline
\end{tabular}

Table B.1. Affective intelligent learning environments

PBL - Problem-Based Learning

GBL - Game-Based Learning

ANN - Artificial Neural Network

HMM - Hidden Markov Models

IA - Intelligent Agent

ITS - Intelligent Tutoring System

VLE - Virtual Learning Environment 


\section{Appendix C. Research Project Plan}

\begin{tabular}{|l|l|}
\hline & Milestones \\
\hline & Designing, testing and deploying phases \\
\hline & Data collection \\
\hline & Experimentation \\
\hline & Background and focal theory \\
\hline & Writing up thesis \\
\hline & Publications \\
\hline & Research training program \\
\hline
\end{tabular}

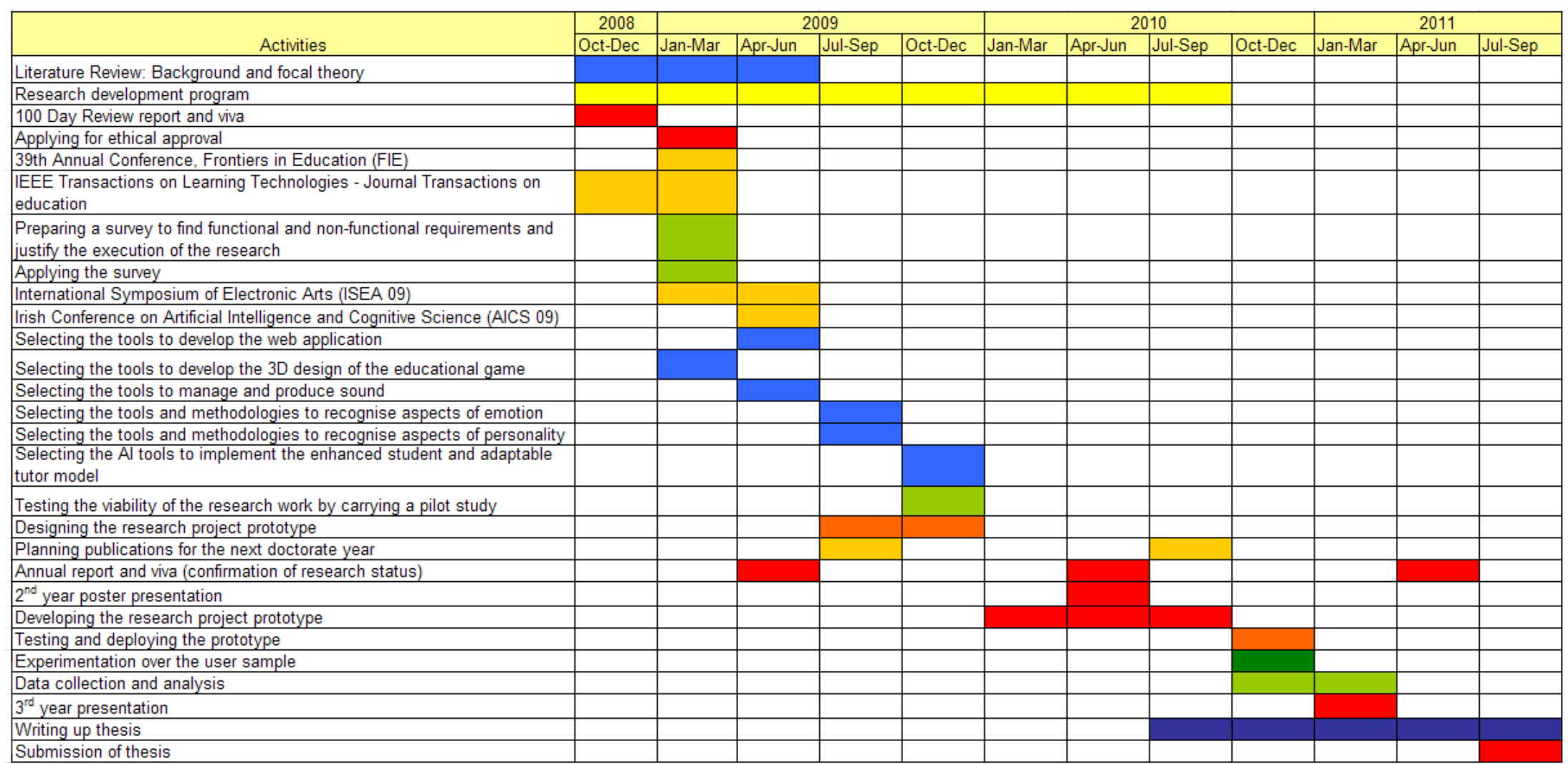

Table C.1. Research plan schedule 